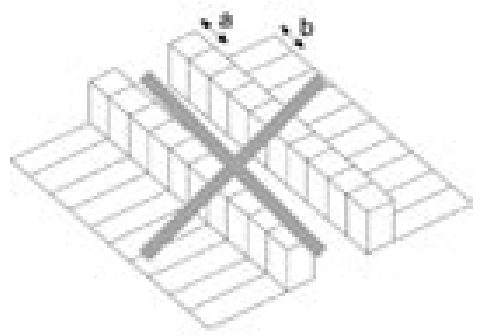

Ancho casa $=$ ancho lote $=$ ancho habitación = hacinamiento
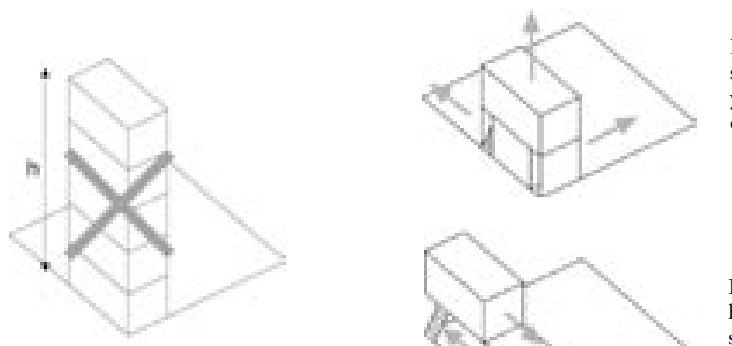

Edificio con sólo el primer y ultimo piso Edificio en altura, no permite crecimie
1 casa $=1$ lote $=$ uso ineficiente del suelo $=$ relegamiento a la periferia
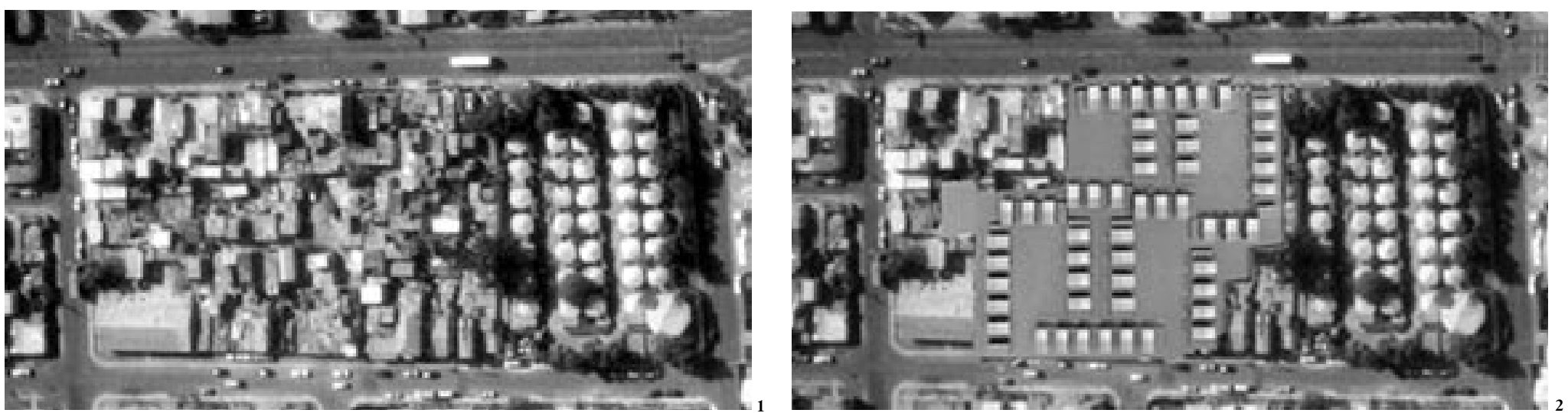

Equipo Elemental

Iquique, Chile

\title{
Quinta Monroy
}

El proyecto para Quinta Monroy constituye una suerte de avanzada del concurso Elemental Chile, que podría generar un modelo aplicable extensivamente: incorpora conjuntos de menor escala a tejidos urbanos consolidados, propone la radicación de las familias en su lugar original de residencia, plantea un estímulo a la integración social por sobre la segregación y supone participación de los habitantes en la toma de decisiones generales. Todo eso además de entregar una visión renovada y viable de la vivienda social en el desierto costero chileno. Palabras clave: Arquitectura - Chile, zonas áridas, vivienda social, concurso
Elemental, vivienda social dinámica sin deuda, programa Chile - Barrio, MINVU

The Quinta Monroy project is a sort of preview of the Elemental Chile competition that could generate a model suitable for wide application.

Incorporating small-scale ensembles in the urban fabric, it would settle families in their original place of residence, stimulate social integration rather than segregation and include participation by residents in general decisionmaking. All this as well as delivering a revitalized and viable vision of social housing for Chile's coastal desert. Key words: Architecture-Chile, arid zones, social housing, Elemental Chile
competition, dynamic debt-free social housing, Chile-Barrio Program, MINVU

\section{Un proyecto seco}

En 2002, fuimos contactados por el Programa Chile-Barrio del Gobierno de Chile, para trabajar en el campamento de Quinta Monroy de Iquique, una ciudad en el desierto chileno. Se nos pedía radicar a las 100 familias que durante los últimos 30 años ocupaban ilegalmente un terreno de media hectárea en el centro de la ciudad.

Lo primero que habría que entender es que el sistema por medio del cual la sociedad chilena ha abordado la provisión de vivienda para la gente de escasos recursos está basado en un subsidio estatal a la demanda, la cual es satisfecha por el mercado. Este subsidio debe cubrir los costos de 3 grandes partidas: el suelo, la urbanización (calles, redes de alcantarillado, agua, electricidad) y la vivienda misma.

El proyecto para Quinta Monroy debía trabajar específicamente en el marco de un nuevo programa del Ministerio llamado Vivienda Social Dinámica sin Deuda (VSDsD), el cual está enfocado a los más pobres de la sociedad, aquellos que no tienen capacidad de endeudamiento. El programa consiste en un subsidio de 300 UF (US\$ 7.500) por familia, entregado por una sola vez $y$ al principio, sin deuda asociada, $y$ que en el mejor de los casos (con un mercado de la construcción bastante eficiente) permite una vivienda de aproximadamente $30 \mathrm{~m}^{2}$. Es decir, si bien la familia queda sin deuda con el Estado, el escaso monto del subsidio obliga a los beneficiarios a ser ellos mismos quienes transformen en el tiempo la mera solución habitacional en una vivienda digna (de ahí el nombre de vivienda dinámica).

Esta condición "dinámica" de la vivienda tiene un posible riesgo y una gran virtud (aún cuando involuntaria).

En primer lugar, hay que hacerse cargo del crecimiento, esto tanto en el sentido de facilitar las operaciones de ampliación, como de evitar la degradación del espacio urbano producto de la precaria calidad de construcción que es dable esperar. Por otra parte, se debe considerar la crítica histórica a la vivienda social: su incapacidad de responder a la diversidad de conformaciones, gustos y sensibilidades de las distintas familias; en la búsqueda de la economía, la tendencia a la repetición y la serialización, se han generado barrios monótonos y de muy mala calidad. Pero en un escenario en que más de la mitad de la superficie habitable serán autoconstruida, la repetición, monotonía y eventualmente la sequedad del núcleo inicial, 

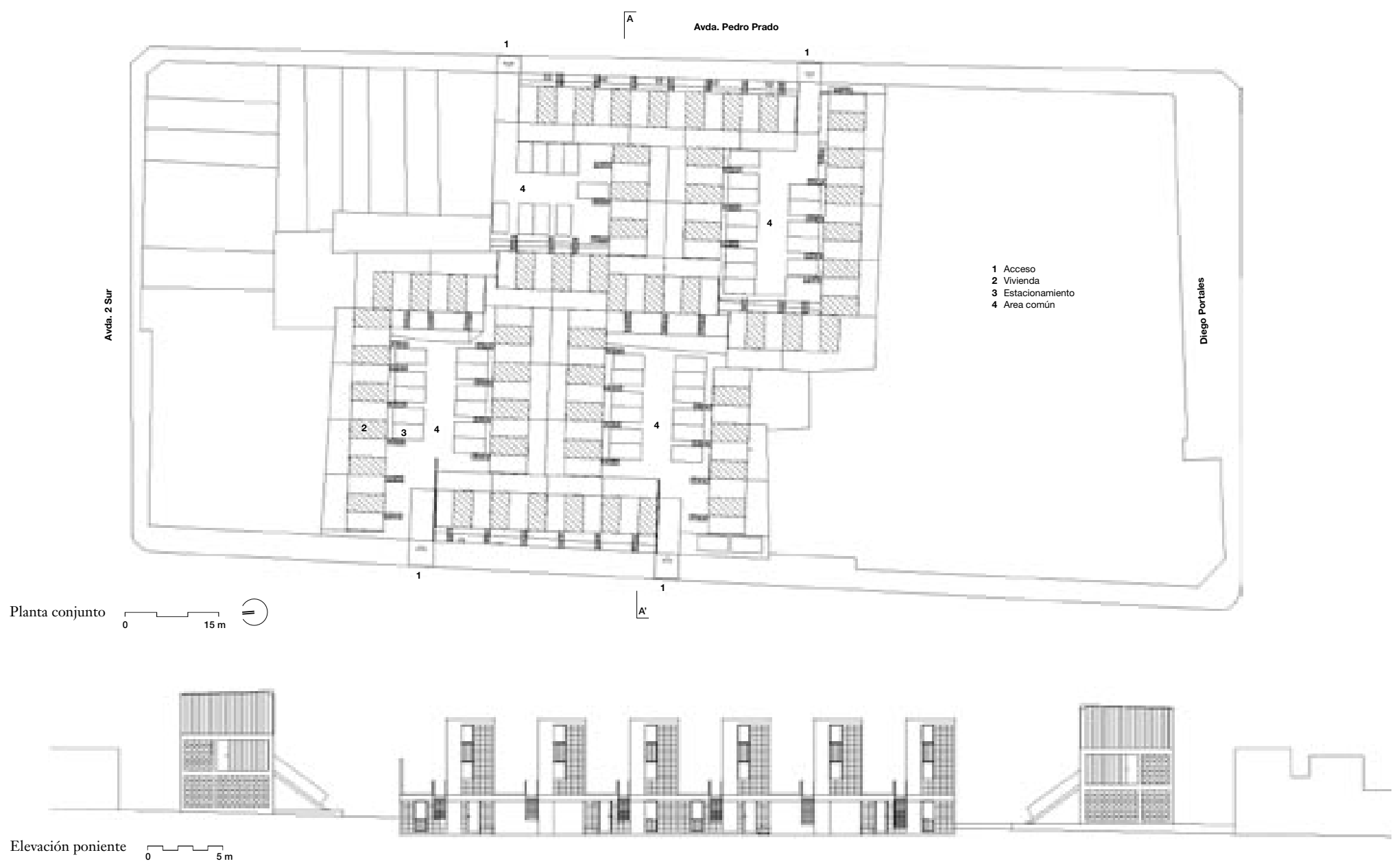

podrían ser la única manera de ordenar un entorno con una alta probabilidad de ser caótico. Con ello la serialización y repetición, ambas grandes fuentes de eficiencia y economía, pasan a ser algo por lo que ya no hay que sentir cargo de conciencia. Involuntariamente, en la dificultad (el escaso monto del subsidio que era posible de "regalar") estaba la solución a uno de los mayores problemas en la historia de la vivienda social.

Ahora bien, lo que hay que tener claro es que el estándar mínimo es el de una vivienda definitiva, y no el de una vivienda provisoria o de emergencia (a pesar del escaso metraje o de niveles de terminación muy básicos).

Por último, lo verdaderamente clave no está tanto en la vivienda misma, sino en el barrio. No sólo como la aspiración a un diseño que permita que el barrio no comience su deterioro al día siguiente de entregadas las casas, y que más bien promueva su valorización en el tiempo (porque por mucho que se invierta en la casa, si el barrio es malo todo se va para abajo). También son fundamentales la buena localización y la cercanía a las redes de oportunidades, que son, en el fondo, lo que una ciudad es: oportunidades de trabajo, transporte, educación, salud, etc. De ahí la importancia del esfuerzo de radicación del campamento que el gobierno nos pedía.

En resumen, podríamos decir que el desafío consistía en diseñar un conjunto arquitectónico capaz de conformar un barrio de calidad, sustentable en el tiempo, que hiciera un uso eficiente del suelo y pudiese así comprar un terreno que, después de 30 años, se había transformado en una localización buena y cara en la ciudad. Esto debía lograrse sin producir hacinamiento, con unidades que pudiesen crecer con facilidad, estructuralmente seguras, todo por 300 UF por familia (US\$ 7.500).

Nuestro primer ejercicio fue ver qué ocurría si tratábamos de contestar la pregunta con las tipologías existentes en el mercado.

Considerando el supuesto 1 casa aislada $=1$ lote (conocido en el mercado como tipo A), el uso del suelo era extremadamente ineficiente: sólo 35 familias en el terreno.

El tren de casas de 2 pisos, el tipo B, iba un poco mejor: 66 familias en el terreno. Pero al reducir el tamaño del lote (a) hasta igualarlo con el de la casa (b) habríamos obtenido, más que densidad o eficiencia en el uso del suelo, sólo hacinamiento. Este esquema, cada vez que se agrega una habitación, va dejando sin luz ni ventilación las habitaciones anteriores.

Por ultimo, el tipo C o block solucionaba la cabida de las cien familias, pero para las VSDsD no constituye una alternativa, pues es una tipología que no permite crecer. Por lo demás, las familias nos hicieron saber que si osábamos solucionar la pregunta entregando blocks, ellos se irían a huelga de hambre.

El resultado de este ejercicio de cabidas era preocupante. No sólo por el drama social que significaba para un número importante de familias tener que trasladarse a la periferia en Alto Hospicio, rompiendo todas las redes de subsistencia (trabajo, salud, transporte, educación) que habían creado luego de 30 años, con el consiguiente riesgo de empeorar aún más su situación de marginalidad; lo verdaderamente duro del ejercicio fue constatar que si reuníamos los subsidios de, digamos, 66 familias, se gastaba tal cantidad de dinero en comprar el terreno, que no quedaban recursos suficientes para urbanizar ni construir.

Entonces lo primero fue cambiar la manera de pensar el problema, reemplazando el diseño de la mejor unidad de 300 UF posible, multiplicada 100 veces, por el mejor edificio de 30.000 UF posible, dentro del cual se albergaran 100 familias en viviendas que pudieran crecer. Pero habíamos visto que un edificio, los propietarios no se pueden ampliar... salvo en el primero y el último piso. 
Trabajamos por tanto en un edificio que tuviera sólo el primer y el último piso. Lo llamamos el Edificio Paralelo debido a su estructura de propiedad: una casa y un departamento en paralelo.

Este edificio debía ser lo suficientemente "poroso", para permitir que la casa en el primer piso creciera horizontalmente sobre el suelo, mientras el departamento en el segundo lo hiciera verticalmente hacia el aire.

Con algo de temor, presentamos a las familias esta tipología. No sabíamos si iban a entender o a estar dispuestos a vivir en una casa con un departamento encima. Se demoraron algo así como 3 segundos en aceptar la proposición. ¿ $\mathrm{La}$ razón? Originalmente a la Quinta Monroy habían llegado 50 familias. Después de 30 años, cada una de ellas había construido sobre la casa inicial un departamento con entrada directa desde la calle, que arrendaban a otras familias. Y tenían más que claro que los primeros pisos tenían las ventajas de una casa (suelo, patio, jardín) y los segundos las ventajas de los departamentos (luz, ventilación y seguridad). Lo que les interesaba mejorar ahora era la división de las propiedades, con buenos muros cortafuegos.

Por último, a escala urbana, se ha buscado introducir entre el espacio público y el privado el espacio colectivo, propiedad común pero de acceso restringido; cuatro especies de plazas, en torno a las cuales viven alrededor de 20 familias, buscan generar las condiciones donde se pueda dar lo que se conoce como familia extensiva, que es la manera en la cual se puede sobrevivir en entornos sociales frágiles.

Quizás el mayor logro de este proyecto, que se terminará de construir en septiembre del 2004, fue lograr radicar a 93 familias en un terreno cuyo valor doblaba lo que normalmente paga la vivienda social, evitando su desplazamiento a la periferia en Alto Hospicio. Esperemos que esta cercanía a las oportunidades contribuya a hacer más corto el camino de estas familias para superar la pobreza. Alejandro Aravena ARQ

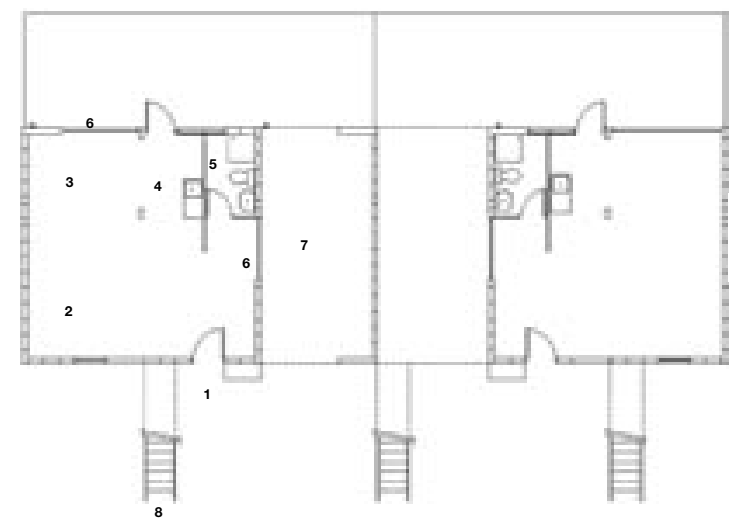

1 Acceso
2 Estar
3 Comedor
4 Cocina

4 Cocina

6 Tabiuue removible
7 Futura anpliaioion
8 Acceso casa a atos

Planta viviendas piso $1 \longdiv { 3 }$

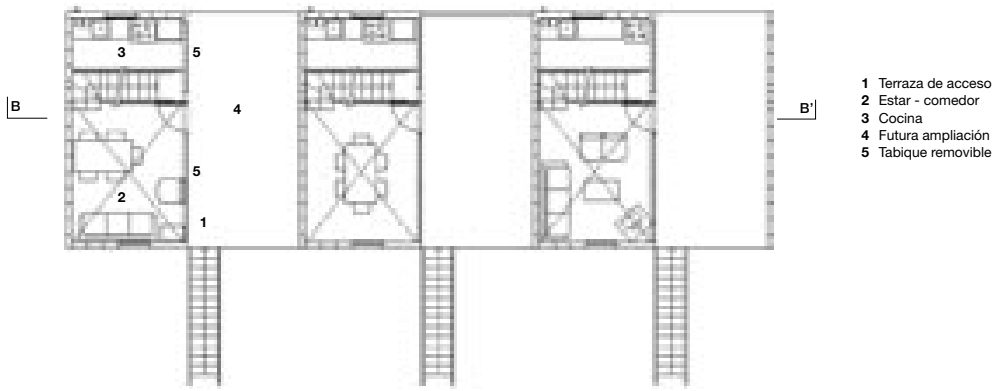

Planta viviendas piso 2

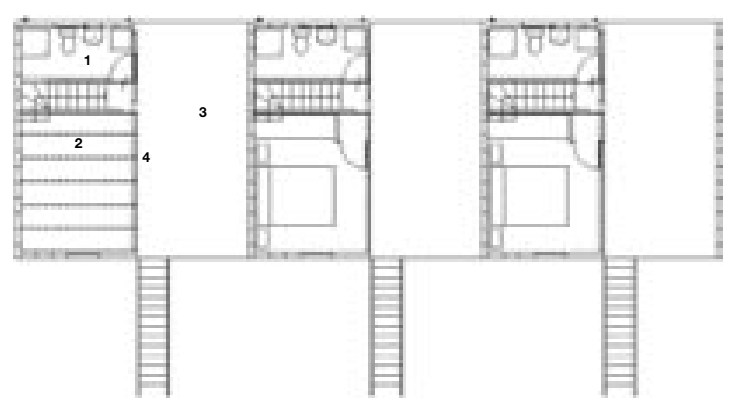

Planta viviendas piso 3

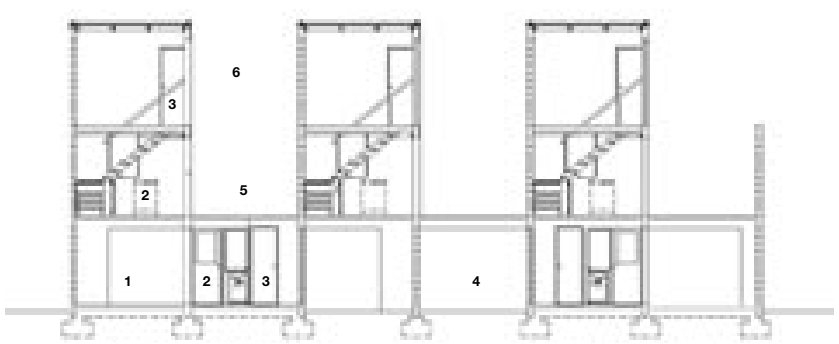

1 Baño
2 Vacio (envigado de
piso seguin cálculo para piso según cálculo para
zona de futura ampliación) 3 Futura ampliación
4 Tabique removible

Corte viviendas - BB'

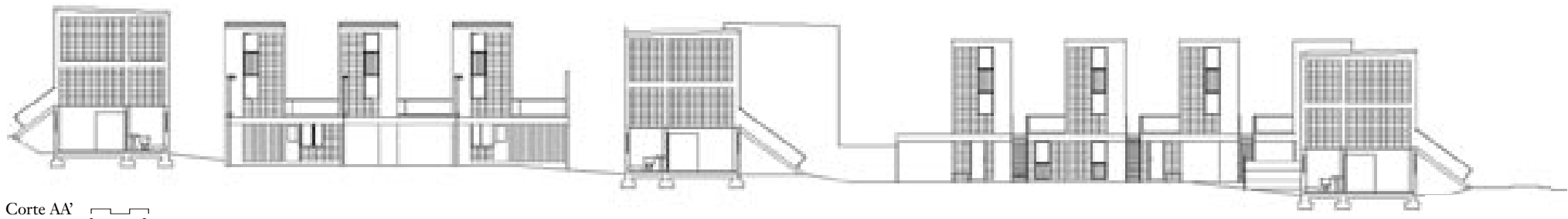


3 y 4 Entre el espacio público de

las calles y el privado de las

casas, introdujimos el espacio

etapas inicial y consolidada
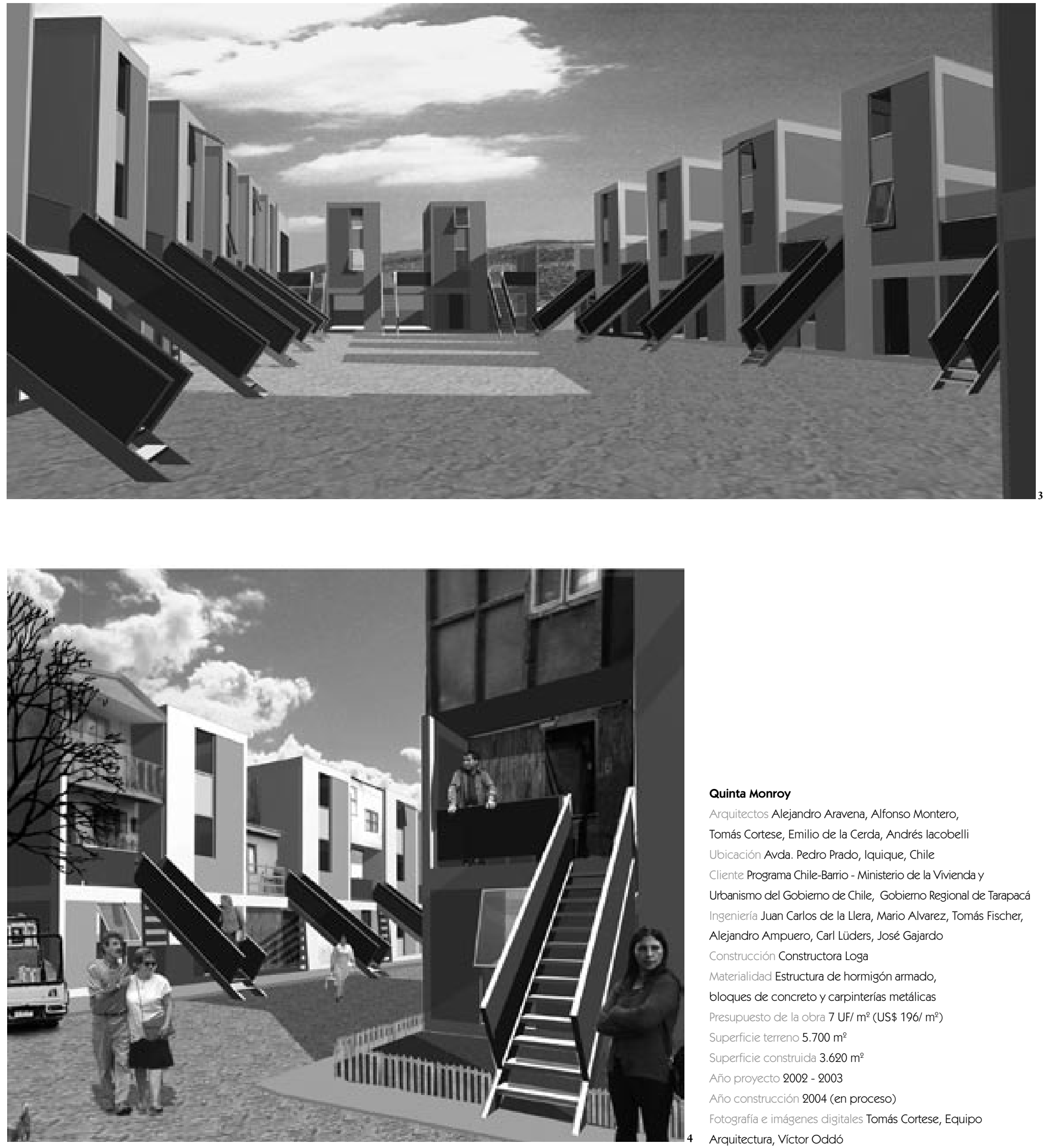

\section{Quinta Monroy}

Arquitectos Alejandro Aravena, Alfonso Montero,

Tomás Cortese, Emilio de la Cerda, Andrés lacobelli

Ubicación Avda. Pedro Prado, lquique, Chile

Cliente Programa Chile-Barrio - Ministerio de la Vivienda y

Urbanismo del Gobierno de Chile, Gobierno Regional de Tarapacá

Inseniería Juan Carlos de la Llera, Mario Alvarez, Tomás Fischer,

Alejandro Ampuero, Carl Lüders, José Gajardo

Construcción Constructora Loga

Materialidad Estructura de hormizón armado,

bloques de concreto y carpinterías metálicas

presupuesto de la obra 7 UF/ m² (US\$196/ m²)

Superficie terreno $5.700 \mathrm{~m}^{2}$

Superficie construida $3.620 \mathrm{~m}^{2}$

Año proyecto 2002 - 2003

Año construcción 2004 (en proceso)

Fotografía e imásenes digitales Tomás Cortese, Equipo

Arquitectura, Víctor Oddó 